\title{
أسباب تدني اكتساب طلبة المرحلة الثانوية للمفاهيم الفيزيائية من وجهة نظر المعلمين في مديرية التربية والتعليم للواء قصببة اربد
}

\author{
حسين علي الحسين السعيدين \\ دكتوراه في مناهج وأساليب تدريس العلوم- مدير تربية وتعليم- وزارة التربية والتعليم- الأردن \\ hsaideen1962@yahoo.com
}

DOI: https://doi.org/DOI:10.31559/EPS2020.8.1.7

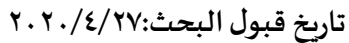

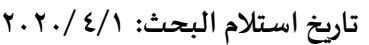

هدفت هذه الدراسة إلى الوقوف على أسباب تدني اكتساب طلبة المرحلة الثانوية للمفاهيم الفيزيائية في مديرية التربية والتعليم للواء قصببة اربد، حيث استخدم المنهاج الوصفي المستي من خلال توزيع استبانه متدرجة حسب مقياس ليكرت الخماسي واشتملت على أربعة مجالات: ( مجال

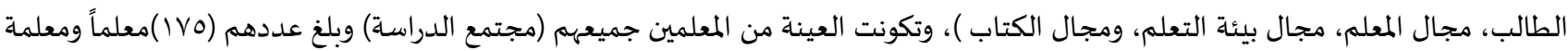
وهم الذين يدرسون مبحث الفيزياء للمرحلة الثانوية في مديرية التربية والتعليم للواء قصبة اربد، في الفصل الدراسي الثاني من العام الدراسي

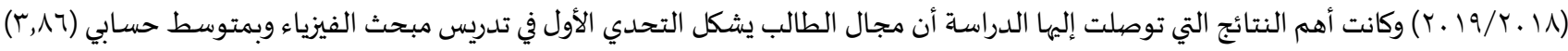

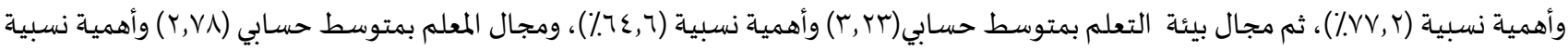

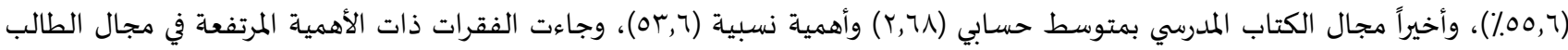

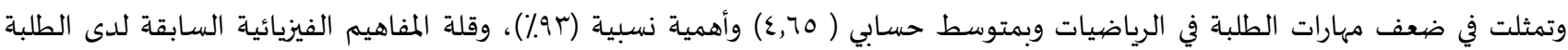

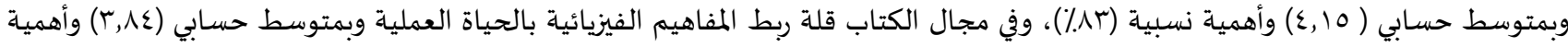

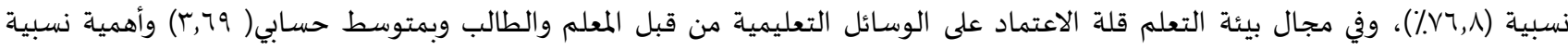

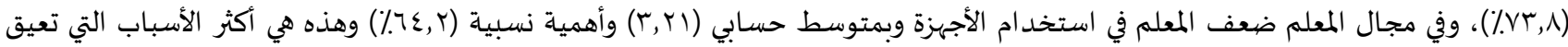

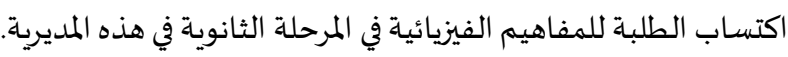

الكلمات المفتاحية: مبحث الفيزياء للمرحلة الثانوية؛ المفاهيم الفيزيائية؛ تدني اكتساب المفاهيم الفيزيائية؛ مديرية التربية والتعليم للواء قصبة اربد (ㄷ) (1)

المقلدمة:

يرى المجتمع العالمي في العصر الحاضر أن التطور الحضياري مرهون بالاهتمام بتدريس العلوم بشكل عام وبتدريس الفيزياء بشكل خاص ولمواكبة هذا التطور ومتطلباته لا بد من الاهتمام بالمرحلة الثانوية كونها المرحلة الهائية في السلم الدراسي المدرسي مما يلزم المزيد من الاهتمام بها

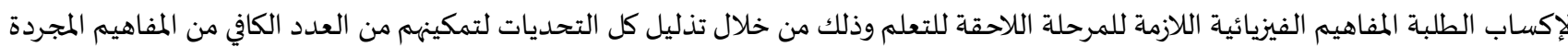

وغير المحسوسة والتي تمكنهم من الالتحاق بالمرحلة الجامعية بسهولة. ويمكن القول أن الوقوف على صعوبات تدريس مبحث الفيزياء يعد عامل من عوامل النجاح في تدريسه، فالمدرس الناجح هو الذي يهتم بتحديد تلك الصعوبات التي تواجاء الطلبة في التدريس وإيجاد الحلول المناسبة لها مما يساعده على إكساب طلبتاه المفاهيم اللازمة لهم وهو من يستطيع توفير المناخ المناسب في غرفة الصف لتعلم أفضل، فيناقش طلبته بما يعرض من آراء وعبارات تتضمن مفاهيم وما يتضمن كتاب الفيزياء من أفكار ومعتقدات تحتمل الخطأ، ويوفر لهم فرصة التعبير عن آرائهم والقيام بالأعمال والمشاريع وحل المشكلات ويدربهم على ممارسة الاتجاهات العلمية

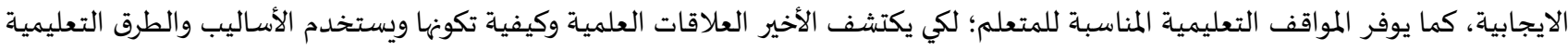

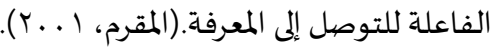




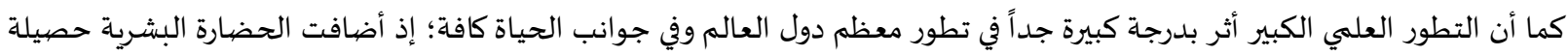

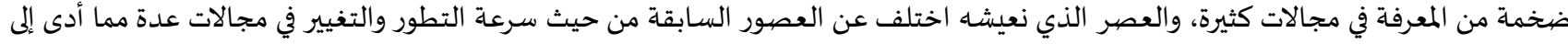

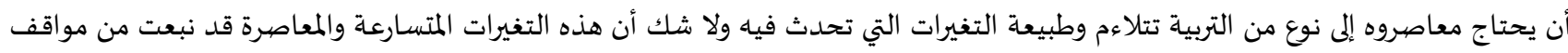

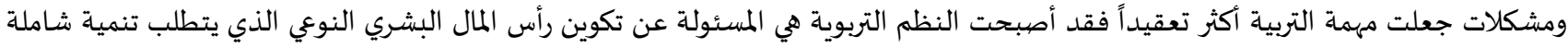

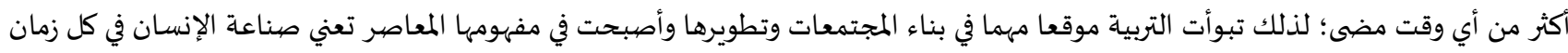

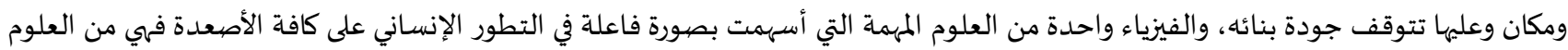

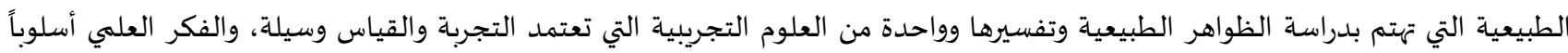

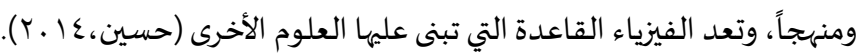

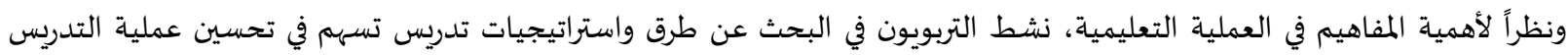

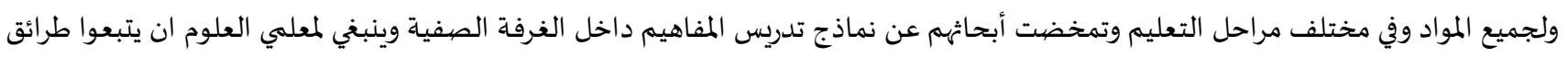

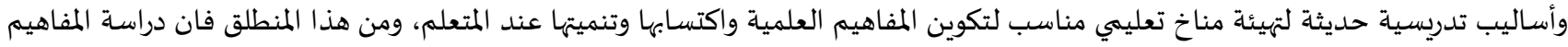

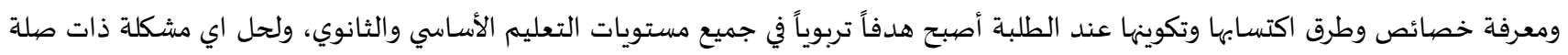

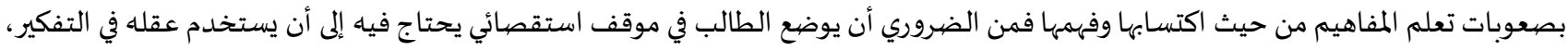

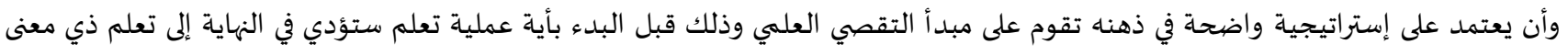

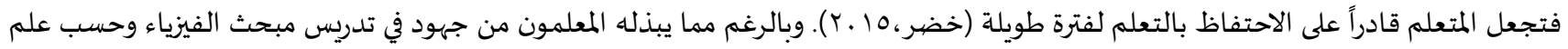

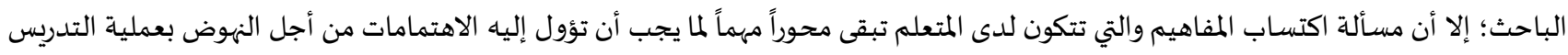

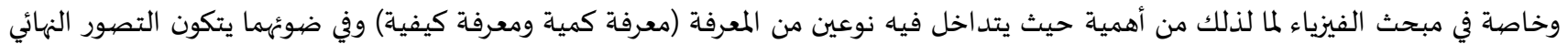

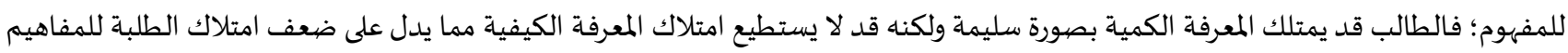
الفيزيائية بصورة صحيحة.

مشكلة الدراسة:

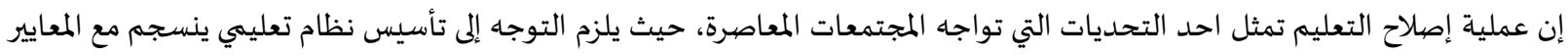

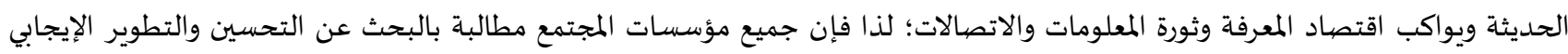

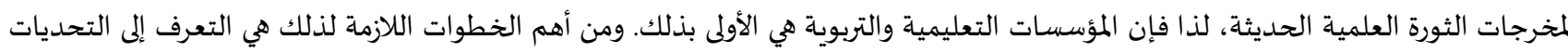

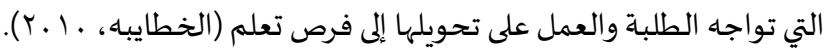

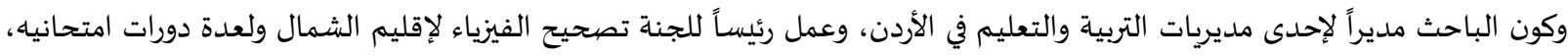
وبالأصل تخصصها في البكالوريوس فيزياء وقد درّّ مبحث الفيزياء لجميع الصفوف والمراحل ولسنوات عدة تمكّكن من الاطلاع على نتائج الطلبة في

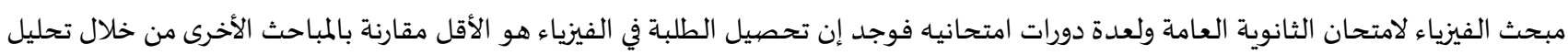

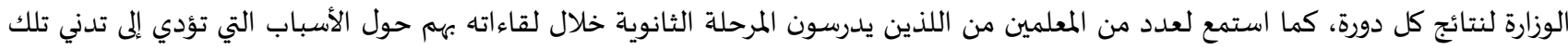

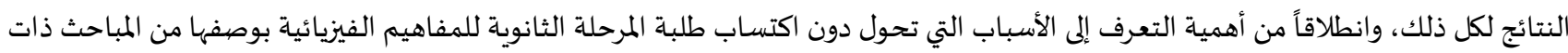

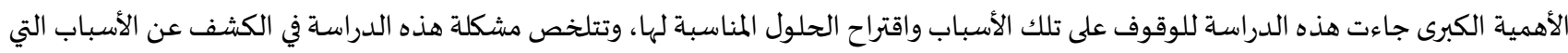

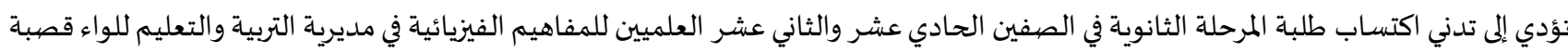
اربد من خلال توزيع استبانه غطت مجالات العملية التعليمية الأربعة وهي:

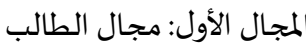

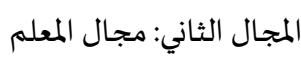

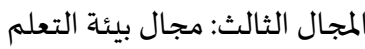

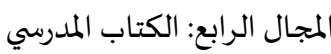
وكل فقرة من فقرات الاستبانه اشتملت على خمسة بدائل (متدني بشكل كبير جداً، متدني بشكل كبير، متدني بشكل متوسط، متدني بشكل قليل،غير متدني) أسئلة الدراسة: الدراسة الحالية ستحاول الإجابة على السؤال التالي: - الئل 
ما هي أسباب تدني اكتساب طلبة المرحلة الثانوية للمفاهيم الفيزيائية في الصفين الحادي عشروالثاني عشر العلميين في مديرية التربية والتعليم للواء قصببة اربد من وجهة نظر المعلمين

أهمية الدراسـة:

تتمثل أهمية الدراسـة في:

الكشف عن الأسباب التي تواجه عملية التدريس لمبحث الفيزياء في المرحلة الثانوية في ظل العملية التعليمية التي تركز على تثبيت المفاهيم والمبادئ التربوية والمعلومات في عقول الطلبة ورفدهم بالخبرات التي تساعدهم على اكتساب المفاهيم.

التعرف إلى آراء معلمي المرحلة الثانوية حول الأسباب التي تحول دون إيصال المفاهيم بالصورة الصحيحة إلى الطلبة. بيان أهمية التعرف إلى آراء المعلمين حول الأسباب التي تؤدي إلى تدني اكتساب طلبة المرحلة الثانوية للمفاهيم الفيزيائية والتي تحول دون تأدية أدوارهم بالشكل الصحيح للابتعاد عن التدريس التقليدي والتنويع في استراتيجيات التدريس والتقويم الحديثة مؤكدين على أن الطالب محور

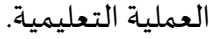

حدود الدراسـة:

الحدود البشرية: اقتصار الدراسة على معلمي ومعلمات مبحث الفيزياء في المدارس الثانوية للصفين الحادي عشر والثاني عشر العلميين. الحدود المكانية: اقتصار الدراسة على المدارس الثانوية في مديرية التربية والتعليم للواء قصبة اربد.

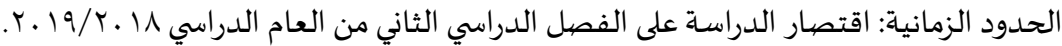

مصطلحات الدراسـة:

مبحثث الفيزياء للمرحلة الثانوية إجر ائياً: جميع مقررات الفيزياء التي حددتها وزارة التربية والتعليم في الأردن لصفوف المرحلة الثانوية بكل ما تحتويه من معارف ومهارات وحقائق ومبادئ ومفاهيم.

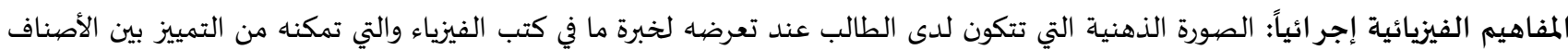
المختلفة والمرتبطة بحياة المتعلم. تدني اكتساب المفاهيم الفيزيائية إجر ائياً: ضعف قدرة طلبة المرحلة الثانوية في اكتساب المفاهيم الفيزيائية وتطبيقها في الحياة العملية مما يتعلمونها في كتابي الصفين الحادي عشر والثاني عشر العلميين لمبحث الفيزياء. مديرية التربية والتعليم للواء قصبة اربد: إحدى مديريات التربية والتعليم في الأردن والتي تتبع وزارة التربية والتعليم الأردنية والتي تعمل على تنظيم العملية التعليمية وتشرف عليها للمدارس الحكومية والخاصة ضهيهن منطقة جغرافية محددة بالمدارس الموجودة داخل حدود لواء قصبية اربد.

الإطار النظري:

تُعد الفيزياء من العلوم الأسـاسية اللازمة لفهم تعقيدات التكنولوجيا الحديثة، وتلزم لمواكبة التقدم التكنولوجي للعالم، حيث تعد مساهمة الفيزياء ذات أثر كبير في العديد من الاختراعات والاكتشافات الحديثة والتي يبنى عليها العلم الحديث؛ كما وقد تسـاعد في تفسير الكثير من الأحداث التي

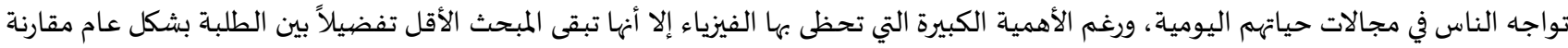

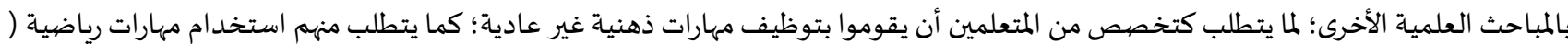
الجبر والهندسة والحساب)، والانتقال من المحسوس إلى المجرد؛ مما يجعل تعلم الفيزياء صعباً بشكل خاص للكثيرين من الطلبة.

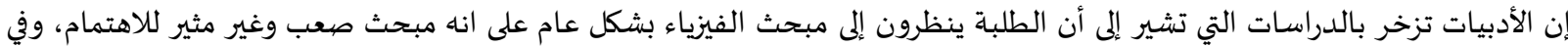

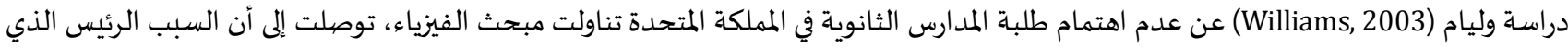
يقدمه الطلبة هو أنهم يعتبرون مبحث الفيزياء مبحثاً صبعباً ويتوقعون بان قدرتهم علمه على فهم مواضيع في الفيزياء قليلة. كما أن اكتساب الطلبة في المرحلة الثانوية للمفاهيم الفيزيائية تعد من التحديات على الرغم من التقدم العلمي وسيطرة الثورة العلمية في مجالي المعلومات ولاتصالات على حياة الناس بشكل عام وعلى الطلبة بشكل خاص رغم وجود كتاب مخصص لمبحث الفيزياء مستقل للصفين الحادي عشر

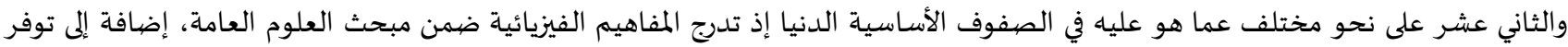

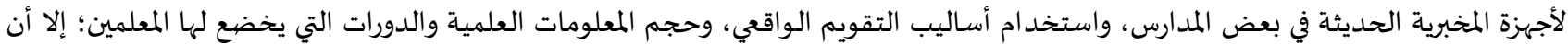

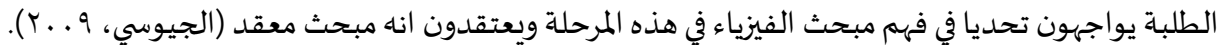


وكذلك في دراسة عليمات (1) ـ ب) التي تناول فيها أثر نموذج العلم المتمازج في دافعية التعلم واكتساب المفاهيم العلمية لدى طلاب الصف التاسع الأساسي، وذلك من خلال إعداد مادة تعليمية في ضوء نموذج تعليمي تعلمي متمازج لتدريس المجموعة التجريبية بينما درست المجموعة

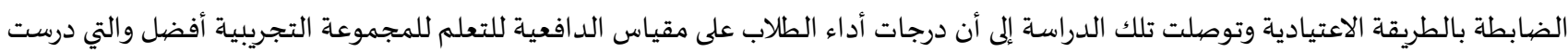
وفق النموذج المعد، وأوصت الدراسة باستخدام النموذج في تدريس الفيزياء. يلاحظ عزوف الطلبة بشكل عام عن اختيار المسار العلمي في المرحلة الثانوية واختيار المسار الأدبي لذلك فان عدد قليل من طلبة الأردن

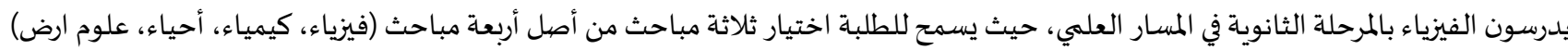

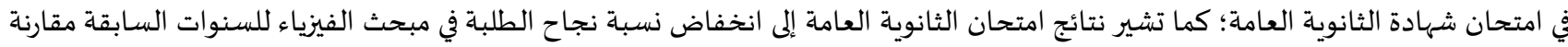

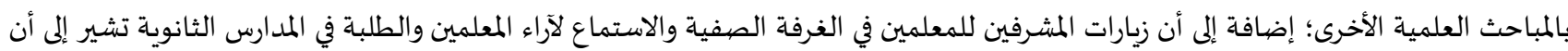
الطلبة يفتقرون لامتلاك المهارات والمفاهيم الأساسية لمبحث الفيزياء في المراحل (الصفوف) السابقة؛ كما أن الطلبة يعتبرون هذا المات المبحث يصبعب

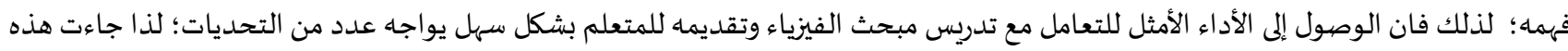
الدراسـة للتعرف على أسباب تدني اكتساب الطلبة للمفاهيم الفيزيائية والتي تواجه المعلمين في تدريس مبحث الفيزياء في المرحلة الثانوية في مديرية التربية والتعليم للواء قصببة اربد.

الدراسات السـابقة: قام أبو صاع و القاسم وعواد (19 ـ ب) بدراسة هدفت إلى تقصي أسباب عزوف الطلاب عن الالتحاق بتخصصيات الفيزياء، والكيمياء، والرياضيات

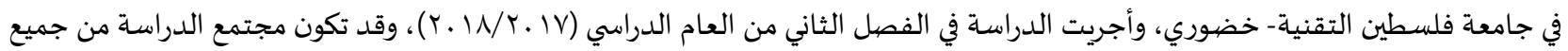

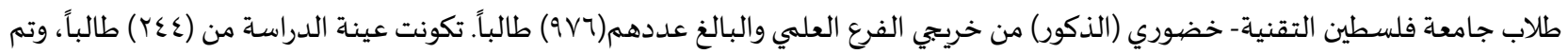
اختيارهم بالطريقة الطبقية العشوائية، ولتحقيق أهداف الدراسة استخدم المنهج الوصفي وذلكية ألك لملاءمته لطبيعة هذه الدراسة. وصهمم الباحثون أداة للدراسـة، وهي استبانه تقيس أسباب عزوف الطلاب عن الالتحاق بتخصصيات الفيزياء، والكيمياء، والرياضيات في جامعة فلسطين التقنية-

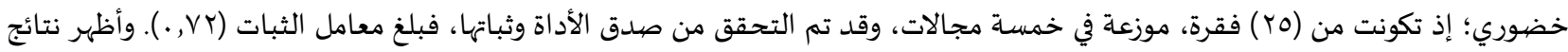

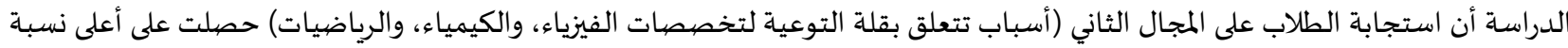

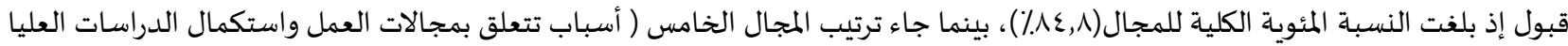

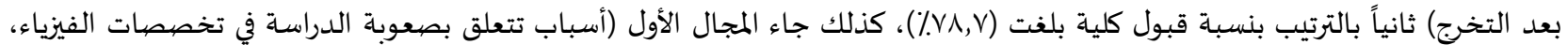

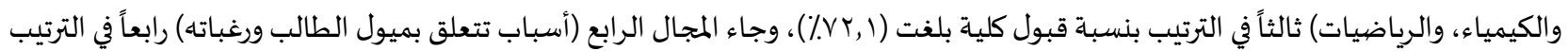

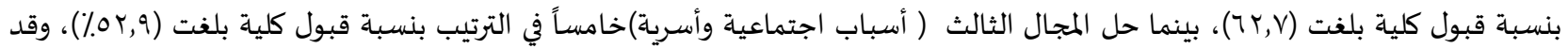

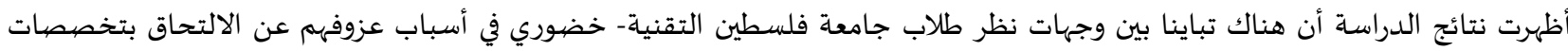

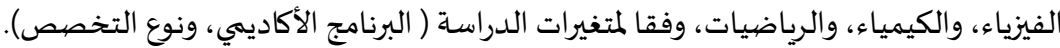

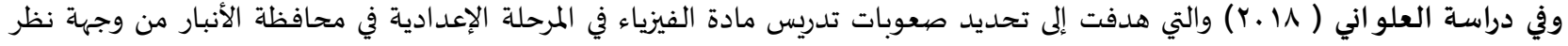

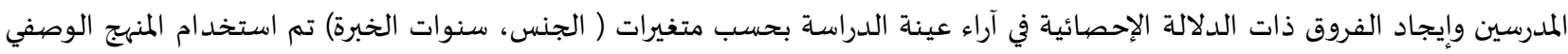
المستي، وتطوير استبانه لقياس صعوبات تدريس مادة الفيزياء اشتملت ستة مجالات ( الأهداف، الكتاب المدرسي، طرائق التدريس، الوسائل

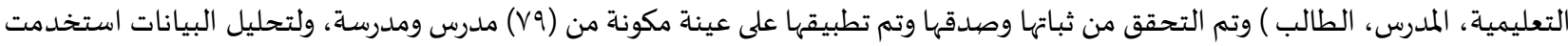

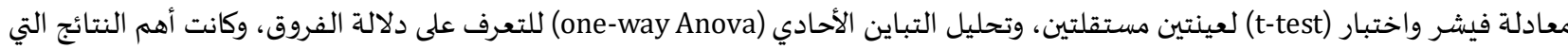

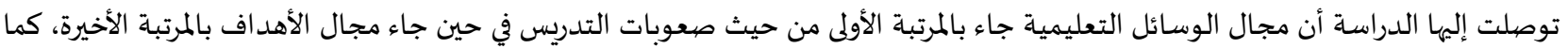
لم تظهر أية فروق ذات دلالة تبعا لمتغير الجنس، وكذلك عدم وجود فروق ذات دلالة تبعا لمتغير سنوات التهبه الخبرة. وكذلك دراسـة قام بها كبر ( r ـ r) حول أسباب عزوف الطلبة عن الالتحاق بالمسار العلمي بالمرحلة الثانوية حيث استخدمت استبانه للتعرف على وجهات نظر المعلمين فتبين أن الأسباب تعود لصعوبة إيصال المفاهيم العلمية المجردة للطلبة؛ وذلك لقلة المختبرات العلمية والأجهزة الحديثة، وأسباب تتعلق بالكتاب المدرسي من حيث طريقة العرض، والإرشاد التربوي المهني للطلبة وتدريب المعلمين النوعي. كذلك دراسة قام بها ستيلا (Stella, 2013) لاستكشاف صعوبة مبحث الفيزياء في المدرسة الثانوية في نيجيريا من وجهة نظر الطلبة، حيث هدفت

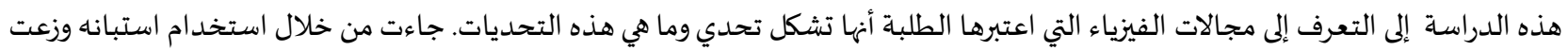

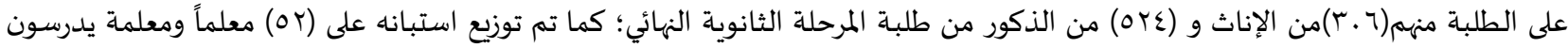

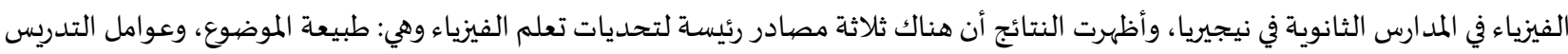


( المعلم والكتاب)، التقييم؛ كما وجد أن الطلبة يواجهون تحدي في فهم موضوعات محددة في الكتاب المدرسي، والتي عادة ما تتميز بافتقارها إلى أمثلة ملموسـة، وتتطلب الكثير من العمليات الرياضية؛ كما وجد الكثير من الطلبة تحدي في حل المشكلات بمفردهم وطرح التساؤلات في الغرفة الصفية.

وفي دراسة العلو اني ( • ـ ا ) جاءت هذه الدراسة للكشف عن الصعوبات التي تواجه مدرس الفيزياء في المرحلة الثانوية ومقترحات وحلول لعلاجها في ليبيا حيث سعت إلى تحديد الأسباب التي تكمن وراء صعوبة تدريس مبحث الفيزياء في المرحلة الثانوية في مدارس ليبيا فأظهرت ان الصعوبات التي تواجه المدرس في تدريس مبحث الفيزياء في المدارس الثانوية تتمثل في: طبيعة المادة، قلة الأجهزة العلمية، عدم استخدام التقنية الحديثة، وطرق التقويم التقليدية.

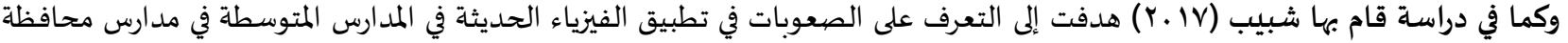

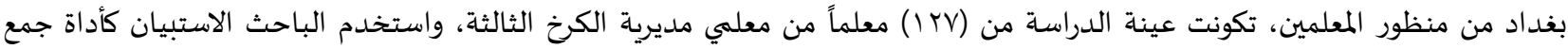
البيانات بعد تطبيقها على المعلمين اللذين خبتهه (0) سنوات فأكثر بعد التأكد من صدق وثبات الأداة، استخدم الباحث المتوسطات الحسابية

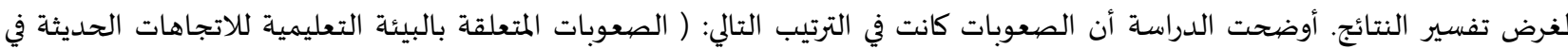
التدريس، الصعوبات المتعلقة بالمنهج، الصعوبات المتعلقة بالطلاب، الصعوبات المتعلقة بالمعلم) وفي ضوء ذلك قدم الباحث مجموعة من التوصيات والمقترحات.

كذلك قام غانم (. ا •Y) بدراسة أثر برنامج محوسب بالخرائط المفاهيمية في معالجة صعوبات تعلم الفيزياء لطلبة الصف الحادي عشر العلمي وذلك من خلال الإجابة على مجموعة من الأسئلة لعينة مكونة من (r7) من طلبة الصف الحادي عشراً لعلمي في مدينة (بيت لاهيا) في فلسطين،

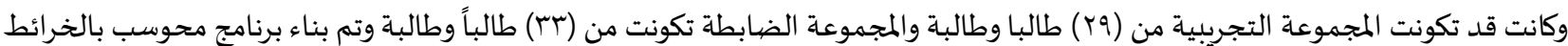
المفاهيمية لدروس وحدة الميكانيكا من كتاب الحادي عشر العلمي، وظهرت النتائج لتلك الدراسة فعالية البرنامج المحوسب ودوره الفعال في معالجة بعض صعوبات التعلم التي تواجه الطلبة في تعلم مبحث الفيزياء. وفي دراسة قام بها الشعيلي (7 . . ج) حول تقصي مجموعة العوامل التي تؤدي إلى تدني تحصيل طلبة الشهادة العامة في التعليم العام للقسم

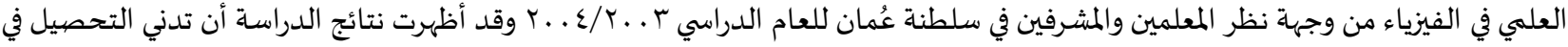

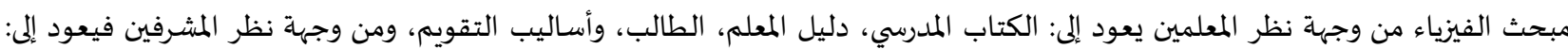

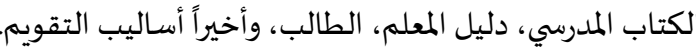
وكذلك دراسة قام بها زوهار (Zohar, 2005) تناولت أسباب تدني مشاركة الطالبات في الحصة الصفية من وجهة نظر معلمات الفيزياء حيث

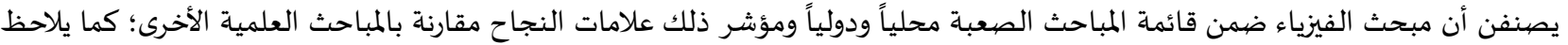

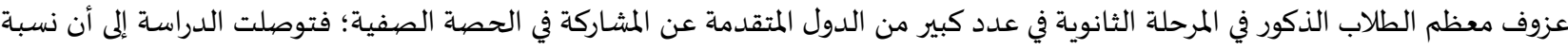
عزوف الطالبات كبير عن المشاركة داخل غرفة الصف وعليه أوصت الدراسة بالبحث عن طرق تساعد المعلمين على تدريس مبحث الفيزياء وتجعلها أكثر تشويقا للطلبة.

وفي ضوء الدراسات السابقة يجد الباحث أن معظم الدراسات تشير نتائجها إلى أن طريقة التدريس وإعداد المادة التعليمية لهما أثر بالغ في

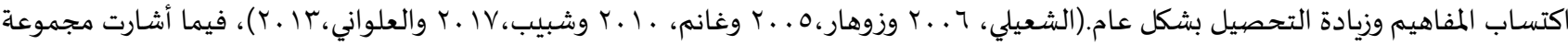

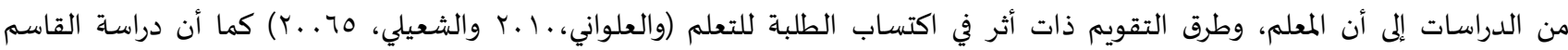

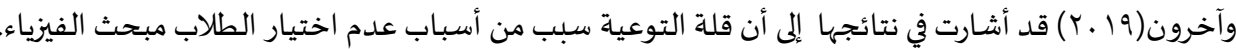

الطريقة والإجراءات: منهجية البحث:

استخدمت الدراسـة المنهج الوصفي التحليلي كونه هو الأكثر ملاءمة للأهداف التي اختيرت الدراسـة من أجله حيث تم جمع البيانات عن طريق

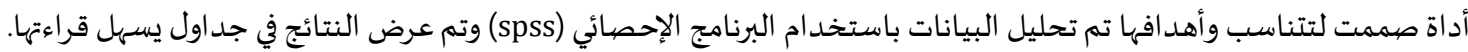

مجتمع الدراسة وعينتها:

تكوّن مجتمع الدراسـة من جميع معلمي ومعلمات الفيزياء اللذين يدرسون الصفين الحادي عشر والثاني عشر العلميين في المدارس الثانوية في

مديرية التربية والتعليم للواء قصبة اربد وعددهم(IV0) معلماً ومعلمة وقد كانت عينة الدراسة هي نفسها مجتمع الدراسة وكان عدد الاستجابات الصالحة للتحليل (170) استجابة فقط لون. 
أداة الدراسـة:

الصيورة الأولية لأداة الدراسـة:

تكونت أداة الدراسـة في صورتها الأولية من استبانه مكونه من (Yo) فقرة لقياس أسباب تدني اكتساب الطلبة للمفاهيم الفيزيائية والتي تواجه

المعلمين والمعلمات في تدريس مبحث الفيزياء للصفين الحادي عشر والثاني عشر العلميين، وتم توزيعها إلى أربعة مجالات هي ( مجال الطالب، مجال

المعلم، مجال بيئة التعلم، مجال الكتاب المدرسي )

صدي أداة الدراسة:

لقد تم التحقق من صدق الأداة بعرضها على ( ـ ) محكمين من القادة التربويين المتخصصيين في الفيزياء في وزارة التربية والتعليم وقد طلب إليهم

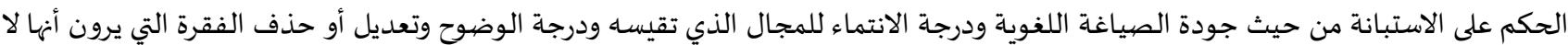
تحقق هدف الاستبانه وبعد جمعها تم إعادة صياغة فقراتها وفق ما تم الاتفاق علياء من قبل المحكمين وبه بلغ عدد الفقرات المتفق عليها (Y (Y) فقرة. ثبات أداة الدراسـة: تصدئ تم التحقق من الاتساق الداخلي لأداة الدراسة باستخدام معادلة كرونباخ ألفا والجدول ( إهاء ) يوضح ذلك. الصورة النهائية لأداة الدراسة: أصبحت أداة الدراسة استبانه تتألف من (Yr) فقرة موزعاة على أربعة مجالات كما في الجدول أدناه: جدول (1): معاملات كرونباخ ألفا لجميع مجالات الدراسة

\begin{tabular}{|c|c|c|c|}
\hline كرونباخ ألفا & عدد الفقرات & المجال & الرقم \\
\hline . & 7 & الطالب & 1 \\
\hline.,$\wedge 7$ & 7 & المعلم & $r$ \\
\hline., 91 & $\varepsilon$ & بيئة التعلم & r \\
\hline.,$\Lambda \Lambda$ & 7 & الكتاب المدرسي & $\varepsilon$ \\
\hline
\end{tabular}

يظهر الجدول(1) أن معاملات كرونباخ ألفا لجميع مجالات الدراسة تراوحت بين ( 17,. . - rq, . ) كان أعلاها مجال الطالب وأدناها مجال المعلم وهي قيم مقبولة لأغراض الدراسة.

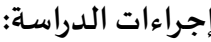
قام الباحث في دراستاء بإتباع الخطوات التالية: أخذ الموافقة من وزارة التربية والتعليم على إجراء الدراسة. اختيار عينة الدراسـة من معلمي ومعلمات الفيزياء في مديرية التربية والتعليم للواء قصبية اربد. بناء أداة الدراسة وحساب صدقها وثباتها. توزيع الاستبانه من قبل المشرفين على المعلمين والمعلمات. جمع البيانات من الاستجابات وتحليلها وإجراء المعالجات الإحصائية اللازمة. مناقشة النتائج وصياغة التوصيات المناسبة في ضوء تلك النتائج. ولقد طلب من افرد عينة الدراسة اللذين سيجيبون على فقرات الاستبانة من المعلمين والمعلمات أن يقدروا من وجهاة نظرهم درجة أهمية

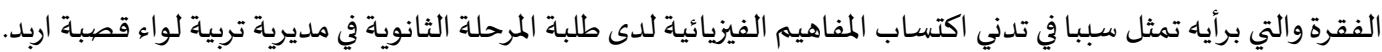
تصحيح المقياس: استخدم الباحث مقياس ليكرت الخماسي بهدف قياس آراء أفراد عينة الدراسة حيث أعطيت قيمة رقمية كالآتي: متدني بشكل كبير جداً(ه)، متدني

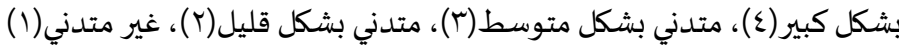

النتائج:

هدفت هذه الدراسة إلى معرفة أسباب تدني اكتساب طلبة المرحلة الثانوية للمفاهيم الفيزيائية من وجهة نظر المعلمين والمعلمات في مديرية التربية والتعليم للواء قصبة اربد.

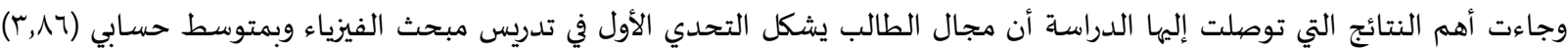

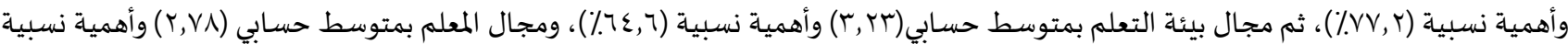

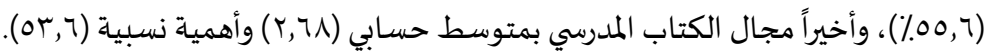


وللحكم على المتوسطات الحسابية لتقديرات أفراد عينة الدراسة ولتوفير مقارنات دقيقة بين تلك الاستجابات تم الاعتماد على معيار من تصيميم الباحث اعتمد فيه أن العلامة (0ء.) فما دون لكل استجابة على الفقرة تعتبر منخفضة بينما العلامة التي تنحصر ما بين أكبر من (0ءء)) وأقل

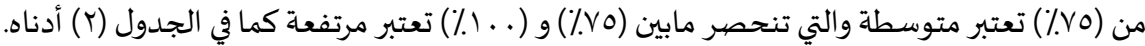

جدول (Y): درجة الأهمية لاستجابة أفراد عينة الدراسة

\begin{tabular}{|c|c|c|}
\hline درجة الأهمية & مدى الدرجات المقبول & الدرجة \\
\hline مرتفعة & $0-r, V_{0}$ & $r$ \\
\hline متوسطة & $r, V \varepsilon-r, r \tau$ & r \\
\hline منخفضة & r, ro- 1 & 1 \\
\hline
\end{tabular}

ولقد جاءت نتائج الدراسة على النحو الآتي: تم حساب المتوسطات الحسابية والأوزان المئوية للأهمية النسبية لاستجابة إفراد عينة الدراسة لأسباب تدني اكتساب طلبة المرحلة الثانوية

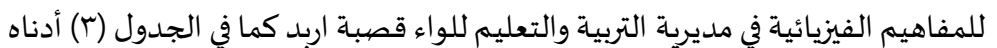

جدول (r): المتوسطات الحسابية والأوزان المئوية للأهمية النسبية لمجالات الدراسة الأربعة

\begin{tabular}{|c|c|c|c|c|c|}
\hline درجة الأهمية & الأهمية النسبية\% & المتوسط الحسابي & المجال & الرتبة & رقم المجال \\
\hline مرتفعة & $V V, r$ & 「,АТ & الطالب & 1 & 1 \\
\hline متوسطة & $7 \varepsilon, 7$ & r, rT & بيئة التعلم & r & $r$ \\
\hline متوسطة & 00,7 & T,VA & المعلم & $r$ & $r$ \\
\hline متوسطة & or,y & $r, 7 \Lambda$ & الكتاب المدرسي & $\varepsilon$ & $\varepsilon$ \\
\hline متوسطة & $7 r, \Lambda$ & $r, 1 \varepsilon$ & \multicolumn{3}{|c|}{ الأداة ككل } \\
\hline
\end{tabular}

يظهر من الجدول أعلاه أن المتوسطات الحسابية لاستجابة المعلمين والمعلمات عن أسباب تدني اكتساب طلبة المرحلة الثانوية للمفاهيم

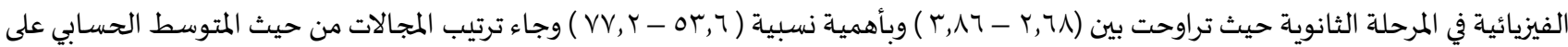

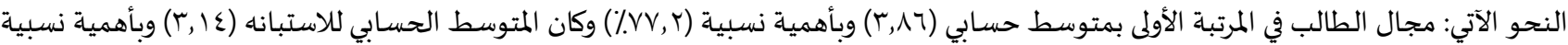

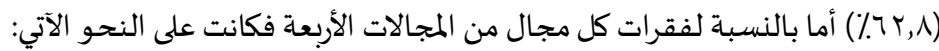
أولاً: مدجال الطالب:

تم حساب المتوسطات الحسابية والأوزان المئوية ودرجة الأهمية لاستجابة أفرادعينة الدراسة في مجال الطالب كما في الجدول (ع)

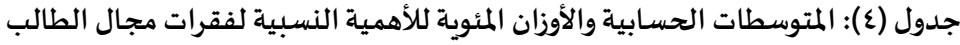

\begin{tabular}{|c|c|c|c|c|c|}
\hline 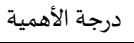 & 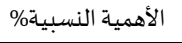 & المتوسط الحسابي & 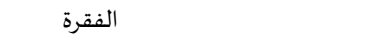 & 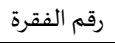 & 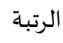 \\
\hline 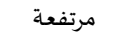 & $q r,$. & $\varepsilon, 70$ & ضعف مهارات الرياضيات لدى الطلبة & r & 1 \\
\hline مرتفعة & Nr,. & $\varepsilon, 10$ & قلة المفاهيم الفيزيائية لدى الطلبة & 7 & r \\
\hline 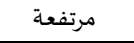 & vo,r & r,v & زيادة عدد الطلبة في الغرفة الصفية & 1 & $r$ \\
\hline متوسطة & vr & $r, 70$ & ضعف الرغبة لدى الطلبة لدراسـة الفيزياء & r & $\varepsilon$ \\
\hline متوسطة & $\vee 1, \Lambda$ & r,09 & ضعف في امتلاك الطلبة للمهارات العلمية & 0 & 0 \\
\hline متوسطة & $7 V, 7$ & r, ז人 & اعتماد الطلبة على الحفظ & $\varepsilon$ & 7 \\
\hline 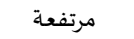 & $V V, r$ & 广,人 & 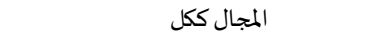 & & \\
\hline
\end{tabular}

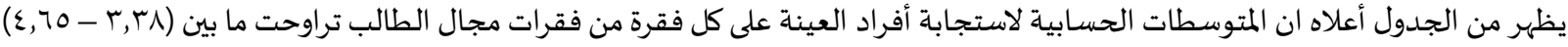

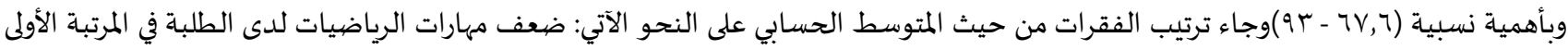

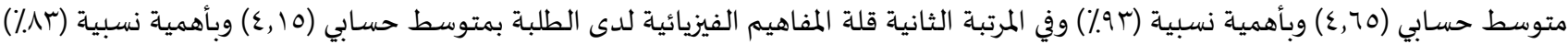

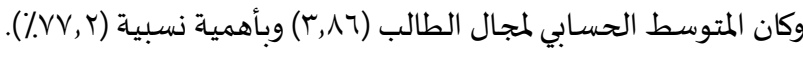

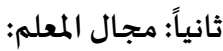

تم حساب المتوسطات الحسـابية والأوزان المئوية ودرجة الأهمية لاستجابة أفراد عينة الدراسة في مجال المعلم كما في الجدول (0)

11. 
جدول (ه): المتوسطات الحسابية والأوزان المئوية للأهمية النسبية لفقرات مجال المعلم

\begin{tabular}{|c|c|c|c|c|c|}
\hline درجة لأهمية & الأهمية النسبية\% & المتوسط الحسابي & 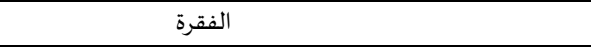 & رقم الفقرة & 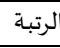 \\
\hline متوسطة & $T \leqslant, Y$ & $r, r)$ & ضعف المعلم في استخدام الأجهزة المخبرية & 9 & 1 \\
\hline متوسطة & $71, \mathrm{r}$ & $r, .7$ & ضعف المعلم في استخدام استراتيجيات التدريس والتقويم الحديثة & 1. & r \\
\hline متوسطة & or, 7 & $r, 7 \uparrow$ & زيادة نصاب المعلم & v & $r$ \\
\hline 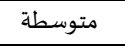 & $0 r, r$ & $r, 77$ & كثرة الدورات التي ليس لها علاقة بتخصص المعلم & 11 & $\varepsilon$ \\
\hline 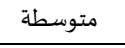 & or,. & $r, 70$ & قلة تعاون الإدارة مع المعلم & ir & $\circ$ \\
\hline متوسطة & $\varepsilon \wedge$, & $r, \varepsilon$. & تدريس مبحث الفيزياء من معلمي التخصصيات الأخرى & $\Lambda$ & 7 \\
\hline متوسطة & 00,7 & $r, \mathrm{VA}$ & المجال ككل & & \\
\hline
\end{tabular}

يظهر من الجدول أعلاه أن المتوسطات الحسابية لاستجابة المعلمين والمعلمات عن كل فقرة من فقرات مجال المعلم تراوحت بين (.ع, - - ب, ب)

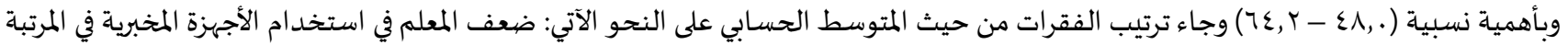

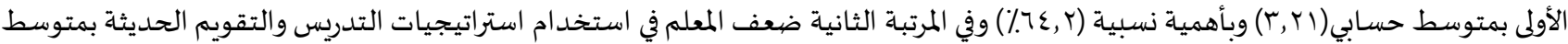

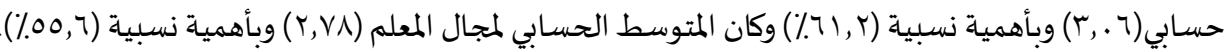
ثالثاً: بيئة التعلم:

تم حساب المتوسطات الحسابية والأوزان المئوية ودرجة الأهمية لاستجابة أفراد عينة الدراسة في مجال بيئة التعلم كما في الجدول (7)

جدول (7): المتوسطات الحسابية والأوزان المئوية للأهمية النسبية لفقرات مجال بيئة التعلم

\begin{tabular}{|c|c|c|c|c|c|}
\hline الأهمية درجة & الأهمية النسبية\% & المستوسط المسي & 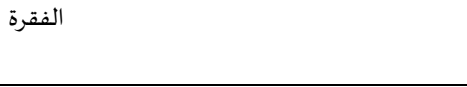 & الفقرة & 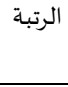 \\
\hline متوسطة & $V r, \Lambda$ & $r, 79$ & قلة الوسائل التعليمية في المدرسة & ir & 1 \\
\hline متوسطة & $r r,$. & $r, 10$ & عدم وجود مختبر أو قيم مختبر في المدرسة & $1 \varepsilon$ & r \\
\hline متوسطة & $7 r, \varepsilon$ & $r, 1 r$ & قلة حصص الفيزياء في الفترة الصباحية على البرنامج & 17 & $r$ \\
\hline متوسطة & $09, r$ & $r, 97$ & بيئة صفية غير مناسبة & 10 & $\varepsilon$ \\
\hline متوسطة & $7 \varepsilon, 7$ & rerr & 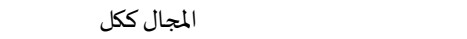 & & \\
\hline
\end{tabular}

يظهر من الجدول أعلاه أن المتوسطات الحسابية لاستجابة المعلمين والمعلمات عن كل فقرة من فقرات مجال بيئة التعلم تراوحت بين (7,97 ب -

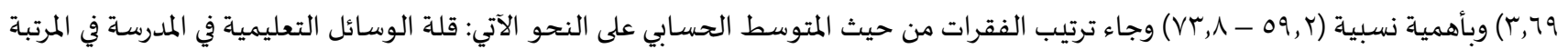

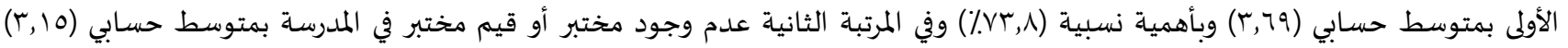

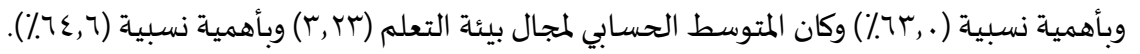
رابعاً: مجال الكتاب المدرسي

تم حسـاب المتوسطات الحسابية والأوزان المئوية ودرجة الأهمية لاستجابة أفراد عينة الدراسة في مجال الكتاب المدرسي كما في الجدول (V) جدول (V): المتوسطات الحسابية والأوزان المئوية للأهمية النسبية لفقرات مجال الكتاب المدرسي

\begin{tabular}{|c|c|c|c|c|c|}
\hline درجة الأهمية & 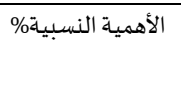 & المتوسط الحسابي & الفقرة & الفقرة & 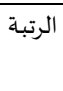 \\
\hline 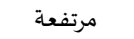 & $\vee \neg, \Lambda$ & 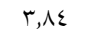 & قلة ربط المفاهيم الفيزيائية بالحياة العملية & 11 & 1 \\
\hline متوسطة & $7 r, \Lambda$ & $r, 1 \varepsilon$ & كثرة المفاهيم الفيزيائية في الكتاب & iv & r \\
\hline متوسطة & 71, & $r, .0$ & كثرة المادة التعليمية وعدم المقدرة على تنفيذ الأنشطة & YI & $r$ \\
\hline متوسطة & $\varepsilon \vee$, & r, ro & المستوى العلمي للكتاب أعلى من قدرات الطالب & 19 & $\varepsilon$ \\
\hline منخفضية & $\varepsilon 1,7$ & $r, \cdot \Lambda$ & قلة استخدام الرسوم والأشكال التوضيحية في الكتاب & tr & $\circ$ \\
\hline منخفضية & $r$ r, & $1,7 \varepsilon$ & قلة تركيز أسئلة الكتاب على المفاهيم الفيزيائية & r. & 7 \\
\hline متوسطة & or, & 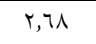 & المجال ككل & & \\
\hline
\end{tabular}

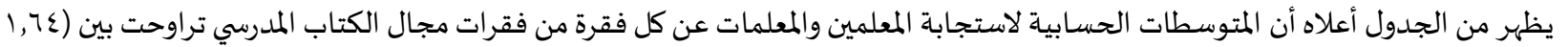

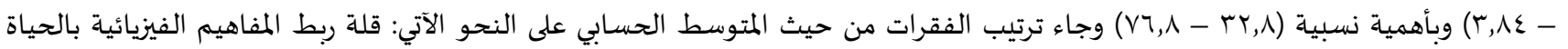

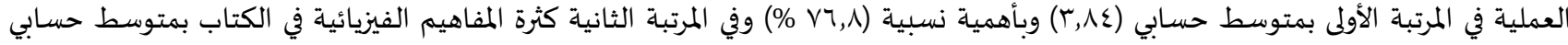

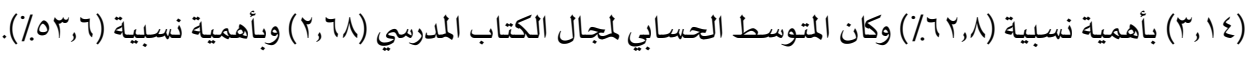


الجدول (^) يظهر أهم الفقرات في جميع المجالات وذات الأهمية المرتفعة والتي تحتاج إلى المزيد من المتابعة من قبل المعلمين والمعلمات والمشرفين التربوين والإدارة التربوية.

جدول (^): يمثل الفقرات ذات الأهمية المرتفعة والمتوسطات الحسابية لها والأوزان المئوية للأهمية النسبية ولجميع المجالات

\begin{tabular}{|c|c|c|c|c|c|}
\hline النسبية\% & المسابي & 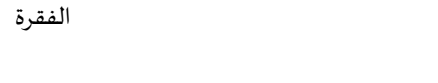 & 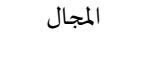 & الفقرة & 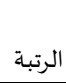 \\
\hline $9 T_{\text {,. }}$ & $\varepsilon, 70$ & ضعف مهارات الرياضيات لدى الطلبة & 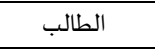 & $r$ & 1 \\
\hline Nr,. & $\varepsilon, 10$ & قلة المفاهيم الفيزيائية لدى الطلبة & 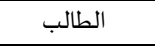 & 7 & $r$ \\
\hline $\mathrm{V}\urcorner, \Lambda$ & $r, \wedge \varepsilon$ & قلة ربط المفاهيم الفيزيائية بالحياة العملية & الكتاب المدرسي & 11 & $r$ \\
\hline vo,r & $r, v 7$ & زيادة عدد الطلبة في الغرفة الصفية & 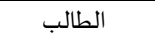 & 1 & $\varepsilon$ \\
\hline $\mathrm{V} r, \Lambda$ & $r, 79$ & قلة الوسائل التعليمية في المدرسة & بيئة التعلم & ir & 0 \\
\hline
\end{tabular}

مناقشة النتائج:

أظهرت النتائج أن أسباب تدني اكتساب طلبة المرحلة الثانوية للمفاهيم الفيزيائية في مديرية التربية والتعليم للواء قصببة اربد تمثلت بالآتي: مجال

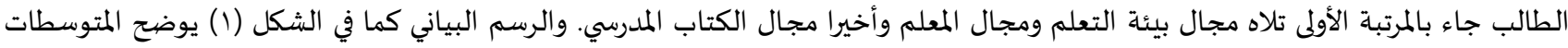

الحسابية للمجالات الأربعة:

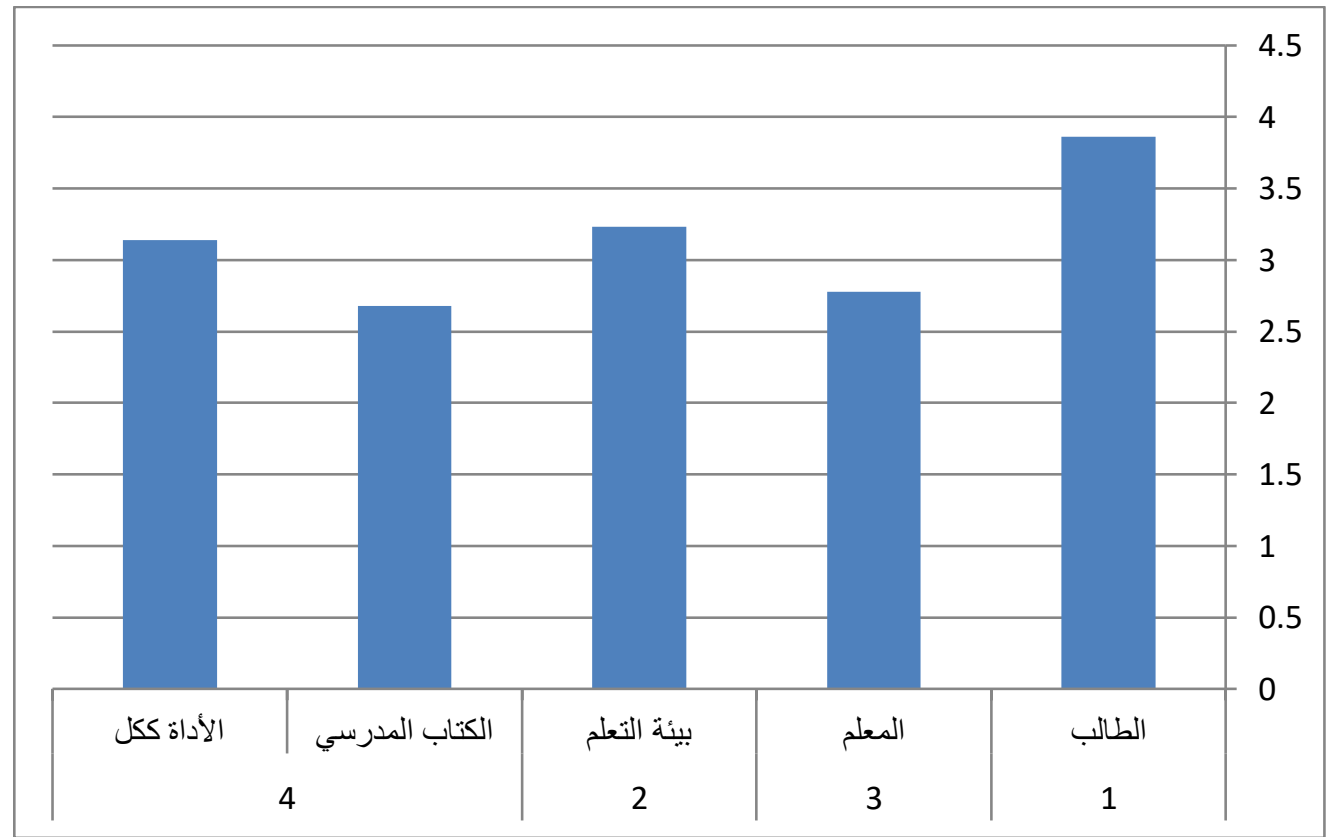

الشكل (1): العلاقة بين المجالات الأربعة لأسباب تدني اكتساب طلبة المرحلة الثانوية للمفاهيم الفيزيائية التي تواجه المعلمين

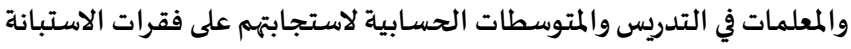

وأما بالنسبة إلى الفقرات لكل مجال فكانت على النحو الآتي: مجال الطالب فيبين الجدول (ع) أن أصعب هذه الفقرات هي ضعف مهارات الرياضيات لدى الطلبة تلاها فقرة قلة المفاهيم الفيزيائية لدى الطلبة، ويعزى ذلك إلى ضعف تأسيس الطلبة في الصفوف السابقة، وضعف الاهتمام بالتكامل العمودي والأفقي للمفاهيم العلمية؛ لقلة استخدام المواد والوسائل العلمية المحسوسة منها والمجردة في تدريس العلوم والفيزياء في السنوات السابقة، وهذا يجعل المعلم أن يكتفي بإعطاء

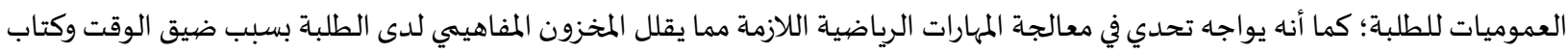
مدرسي يجب أن ينجز ضمن إطار زمني محدد، ومن وجهة نظر الباحث يرى أن يتم الترتيب في نهاية المرحلة الأساسية العليا لعقد امتحان تشرف

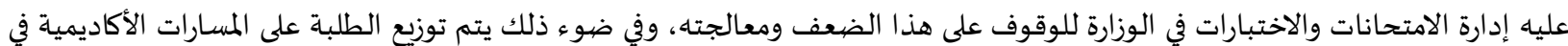
المرحلة الثانويـة. مجال المعلم فيبين الجدول (ه) أن الفقرتين المتعلقتين بضعف المعلم في استخدام الأجهزة المخبرية وتنفيذ التجارب العلمية، وضعف استخدامه

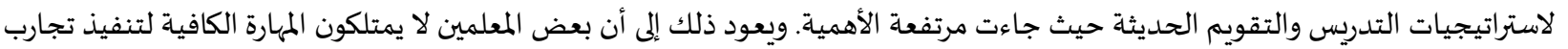
الفيزياء وربط المفاهيم الفيزيائية السابقة بالجديدة؛ لذلك يلجأ إلى إعطاء المفاهيم الفيزيائية باستخدام طريقة التدريس المباشر، والعامل الآخر 
هو أن البعض من المعلمين لا يمتلكون مهارة استخدام استراتيجيات التدريس والتقويم الحديثة والتي من الممكن أن تمكنهم من إكساب الطلبة

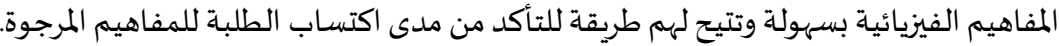

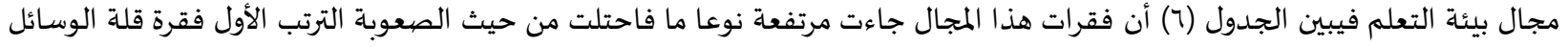

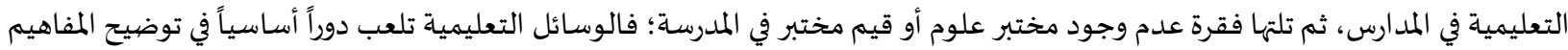

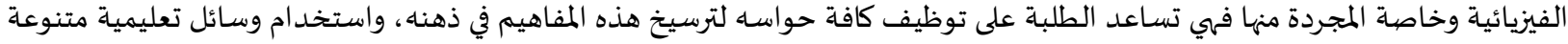

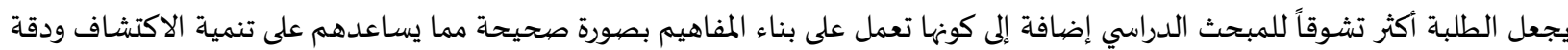

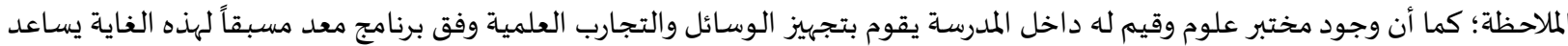

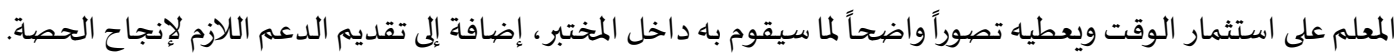

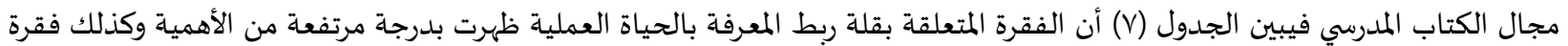

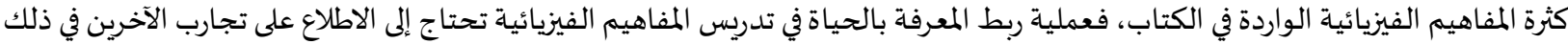

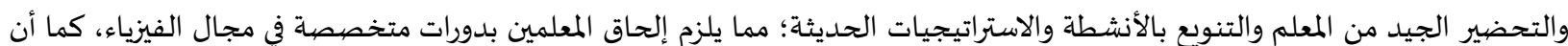

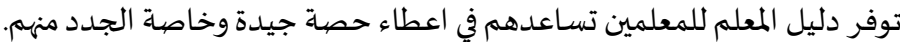

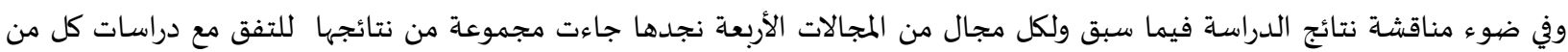

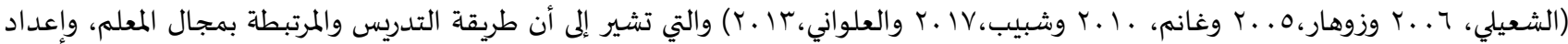

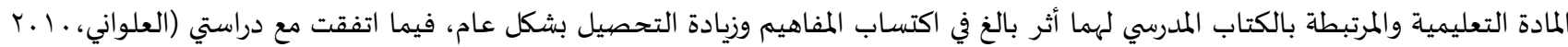

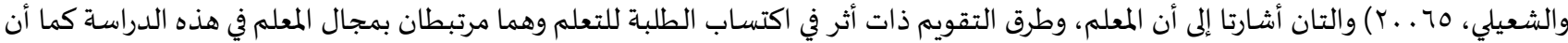

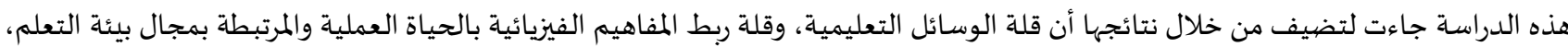
وزيادة عدد الطلبة في الغرفة الصفية، وقلة المفاهيم الفيزيائية السابقة لدى الطلبة والمرتبط بمجال الطالب، واعداد الماديادة التعليمية المرتبط بمجال المعلم، لهم دور أساسي في تدني اكتساب الطلبة للمفاهيم الفيزيائية في المرحلة الثانوية.

التوصيات والمقترحات:

في ضوء نتائج الدراسة فان الباحث يوصي بما يأتي:

اعتماد التدريس وفق المنحى التكاملي لزيادة الاهتمام بالتعرف على المفاهيم الفيزيائية الموجودة لدى الطلبة من المراحل الدراسية السابقة.

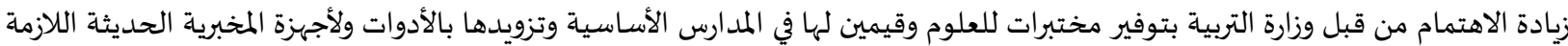
لتنفيذ أنشطة الكتاب المدرسي وذلك لتحقيق مستوى أعلى من الفهم لدى الطلبة في مبحث الفيزياء. هقد دورات تدريبية متخصصية لمدرسي مبحث الفيزياء تركز على كيفية التعامل مع الأجهزة والأدوات المخبرية. عقد دورات إلزامية لمعلمي الفيزياء لاطلاعهم على كيفية توظيف استراتيجيات التدريس وطرق التقويم الحديثة في التعليم التكاملي لتلبية احتياجات الطلبة من المفاهيم التي تلزم تعلمهه.

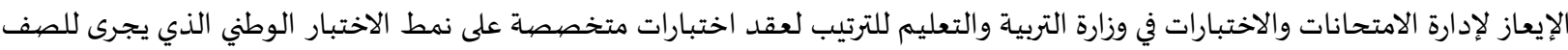

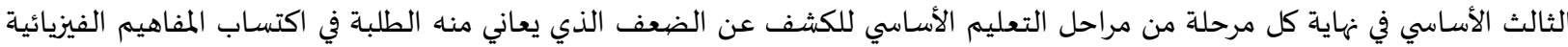
والعمل على إيجاد الحلول المناسبة. التركيز على عنصر التشويق في عرض المفاهيم الفيزيائية في كتاب الطالب وربط المعرفة النظرية الواردة بالكتاب بالمواقف الحياتية واحتياجات الطلبة باستخدام استراتيجيات حديثة في التدريس لتكوين اتجاهات ايجابية لديهم نحو الفيزياء. التعرف إلى كم ونوع الموضوعات التطبيقية والمفاهيم الفيزيائية المجردة والمحسوسة من خلال تحليل دقيق لمحتوى كتب الفيزياء للصفينين التاسع والعاشر اللذين يسبقان المرحلة الثانوية للكشف عن مدى ملائمة تلك المفاهيم لمستوى الطلبة وحاجة الماتهم المستقبلية. إجراء دراسة لتحليل كتب الرياضيات للصفوف التي تسبق المرحلة الثانوية للتعرف على علاقة محتواها المعرفي بما تتطلبه عملية تدريس مبحث الفيزياء في تلك المرحلة.

إجراء الدراسة على عدد من مديريات التربية والتعليم في إقليمي الوسط والجنوب من المملكة الأردنية الهاشمية. إجراء دراسات مماثلة في المباحث العلمية الأخرى (كيمياء، أحياء، علوم ارض، رياضيات) وفي عدد من مديريات التربية والتعليم. 
1. الجيوسي، محمد بلال.(9 . .ب). المعلم الاستراتيجي: اختيار الإستراتيجية المناسبة لكل درس استناداً إلى البحث العلهي. الرياض: مكتب التربية

$$
\text { العربي لدول الخليج. }
$$

Y. حسين، خديجة عبيد.(ع ا .r). "أثر استخدام الخربطة الدلالية في التحصيل والاستبقاء لدى طالبات الصف الثاني المتوسط في مادة الفيزياء".

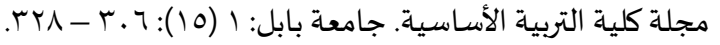

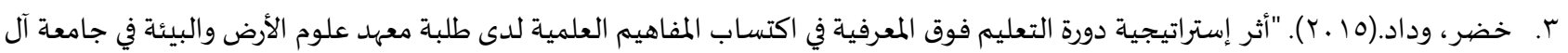
البيت واحتفاظهم بها". رسالة ماجستير غير منشورة. جامعة آل البيت. المفرق.

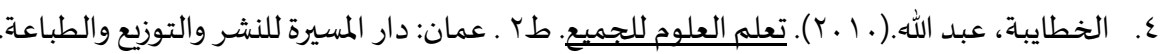

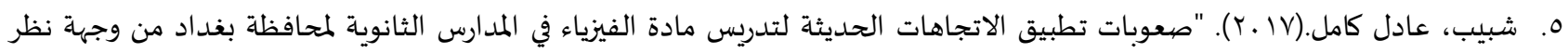

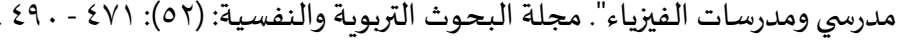

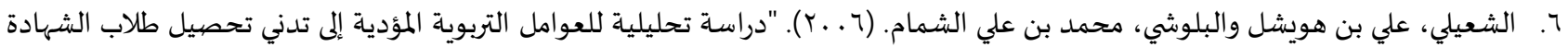

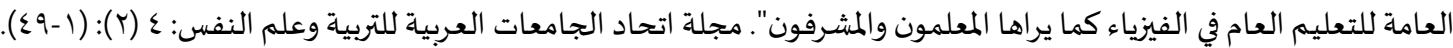

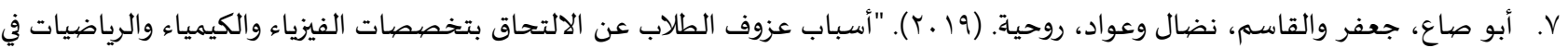

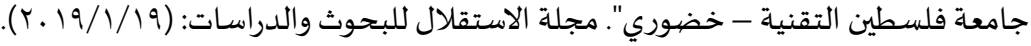

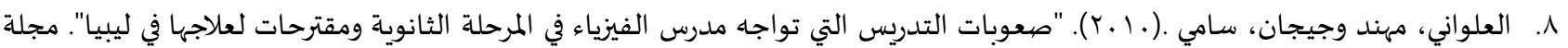

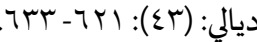

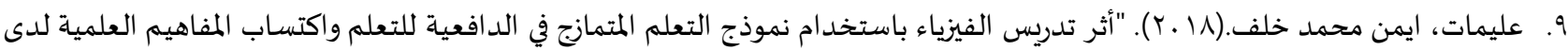

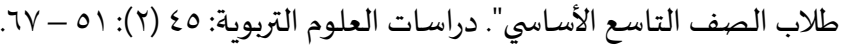

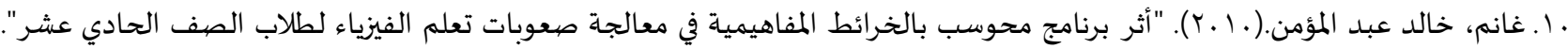

$$
\text { رسالة ماجستير غير منشورة. الجامعة الإسلامية. }
$$

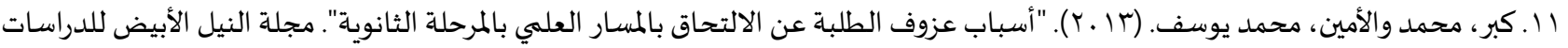

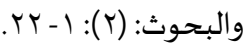

r ا. المقرم، سعد. (11 ـ (Y). طرائق تدريس الفيزياء المبادئوالأهد اف. عمان: دار الشروق.

ثانياً: المراجع الأجنبية:

[1] Stella, y. (2013). “Disciplinary Subjects in Education”. International Journal for Cross-(UCDSE). Special Issue. 3 (3): 1510 1515.

[2] Williams, S., Spall, B. \& Dickson. (2003). “Why A rent Secondary Students Interested in Physics?". Physics Education. 38 (4): 324-329, https://doi.org/10.1088/0031-9120/38/4/306.

[3] Zohar, P. \& Bronshtein, B. (2005). "Physics Teachers Knowledge and Beliefs Regarding Girls Low Participation Rates in Advanced Physics Classe". International Journal of Sciences Education. 27(1): 61-77, https://doi.org/10.1080/0950069032000138798. 


\title{
The reasons for the low secondary school students acquisition of physical concepts from the teachers point of view in Irbid Qasabah district educational directorate
}

\author{
Hussein Ali Al-Hussein Al-saideen \\ $\mathrm{PhD}$ in Curricula and Methods of Teaching Science, Director of Education, Ministry of Education, Jordan \\ hsaideen1962@yahoo.com
}

\begin{abstract}
:
This study aims to stand on the reasons for low acquisition of physics concepts that the teachers of physics point of view while teaching physics to high school students in Irbid Qasabah District Educational Directorate. The descriptive approached was used to collect data through survey the distribution of questionnaire listed according to likert pentatonic scale. The researcher used a questionnaire that includes four domains:(the student, the teacher, the learning environment, and the book) each paragraph includes five alternatives. The sample included all their number (175) the male and the female teachers who teach physics to the high school students Irbid Qasabah District Educational Directorate in the second semester of the academic year (2018/2019). The most important result that the survey indicated was that the students domain was the first challenging in the teaching physics average of arithmetic (3.86) and relative importance (77.2\%) then the learning environment domain average of arithmetic (3.23) and relative importance (64.6\%), teachers average of arithmetic (2.78) and relative importance (55.6\%),. and finally the book domain average of arithmetic (2.68) and relative importance (53.6\%),, the paragraph that showed high frequency was the weakness in arithmetic skills with a rate of (4.65) and the scarcity of physics items and terminology with a rate (4.15) and the lack of linking physical concepts to life a rate of (3.84). With regard to the learning environment the lack of educational aids had the rate of (3.69). With regard to the teacher, the was weak in using the devices the rate of (3.21). These are the reasons that the teachers encounter while teaching physics in Irbid Qasabah District Educational Directorate.
\end{abstract}

Keywords: High school physics; Physical concepts; Low acquisition of physical concepts; Irbid Qasabah District Educational Directorate.

\section{References:}

[1] Al'Iwany, Mhnd Wjyjan, Samy. (2010). "S'wbat Altdrys Alty Twajh Mdrs Alfyzya' Fy Almrhlh Althanwyh Wmqtrhat L'lajha Fy Lybya". Mjlt Dyaly: (43): 621- 633.

[2] 'lymat, Aymn Mhmd Khlf. (2018). "Athr Tdrys Alfyzya' Bastkhdam Nmwdj Alt'lm Almtmazj Fy Aldaf'eyh Llt'lm Waktsab Almfahym Al'Imyh Lda Tlab Alsf Altas' Alasasy". Drasat Al'Iwm Altrbwyh: 45 (2): 51 - 67.

[3] Ghanm, Khald 'bd Alm'mn. (2010). "Athr Brnamj Mhwsb Balkhra't Almfahymyh Fy M'aljh S'wbat T'lm Alfyzya' Ltlab Alsf Alhady 'shr". Rsalt Majstyr Ghyr Mnshwrh. Aljam'h Aleslamyh.

[4] Hsyn, Khdyjh 'byd. (2014). "Athr Astkhdam Alkhryth Aldlalyh Fy Althsyl Walastbqa' Lda Talbat Alsf Althany Almtwst Fy Madh Alfyzya'". Mjlt Klyt Altrbyh Alasasyh. Jam't Babl: 1 (15): 306 - 328.

[5] Aljywsy, Mhmd Blal. (2009). Alm'Im Alastratyjy: Akhtyar Alestratyjyh Almnasbh Lkl Drs Astnadaan Ela Albhth Al'lmy. Alryad: Mktb Altrbyh Al'rby Ldwl Alkhlyj.

[6] Kbr, Mhmd Walamyn, Mhmd Ywsf. (2013). "Asbab 'zwf Altlbh 'n Alalthaq Balmsar Al'lmy Balmrhlh Althanwyh". Mjlt Alnyl Alabyd Lldrasat Walbhwth: (2): 1- 22.

[7] Khdr, Wdad. (2015). "Athr Estratyjyh Dwrh Alt'lym Fwq Alm'rfyh Fy Aktsab Almfahym Al'Imyh Lda Tlbt M'hd 'Iwm Alard Walby'h Fy Jam't Al Albyt Wahtfazhm Bha". Rsalt Majstyr Ghyr Mnshwrh. Jam't Al Albyt. Almfrq.

[8] Alkhtaybh, 'bd Allh.(2010). T'lm Al'lwm Lljmy'. T2. 'man: Dar Almsyrh Llnshr Waltwzy' Waltba'h. 
[9] Almqrm, S'd. (2011). Tra'q Tdrys Alfyzya' Almbad' Walahdaf. 'man: Dar Alshrwq.

[10] Abw Sa', J'efr Walqasm, Ndal W'wad, Rwhyh. (2019). "Asbab 'zwf Altlab 'n Alalthaq Btkhssat Alfyzya' Walkymya' Walryadyat Fy Jam't Flstyn Altqnyh - Khdwry". Mjlt Alastqlal Llbhwth Waldrasat: (19/1/2019).

[11] Alsh'yly, 'ly Bn Hwyshl Walblwshy, Mhmd Bn 'ly Alshmam. (2006). "Drash Thlylyh Ll'waml Altrbwyh Alm'dyh Ela Tdny Thsyl Tlab Alshhadh Al'amh Llt'lym Al'am Fy Alfyzya' Kma Yraha Alm'lmwn Walmshrfwn". Mjlt Athad Aljam'at Al'rbyh Lltrbyh W'lm Alnfs: 4 (2): (1-49).

[12] Shbyb, 'adl Kaml. (2017). "S'wbat Ttbyq Alatjahat Alhdythh Ltdrys Madh Alfyzya' Fy Almdars Althanwyh Lmhafzh Bghdad Mn Wjhh Nzr Mdrsy Wmdrsat Alfyzya'". Mjlt Albhwth Altrbwyh Walnfsyh: (52): 471 - 490.

[13] Stella, y. (2013). "Disciplinary Subjects in Education”. International Journal for Cross-(UCDSE). Special Issue. 3 (3): 1510 1515.

[14] Williams, S., Spall, B. \& Dickson. (2003). “Why A rent Secondary Students Interested in Physics?”. Physics Education. 38 (4): 324-329, https://doi.org/10.1088/0031-9120/38/4/306.

[15] Zohar, P. \& Bronshtein, B. (2005). "Physics Teachers Knowledge and Beliefs Regarding Girls Low Participation Rates in Advanced Physics Classe". International Journal of Sciences Education. 27(1): 61-77, https://doi.org/10.1080/0950069032000138798. 